\title{
Degree of exercise intensity during continuous chest compression in upper-body-trained individuals
}

\author{
Hisayoshi Ogata ${ }^{*}$, Ikuyo Fujimaru and Takaharu Kondo
}

\begin{abstract}
Background: Although chest-compression-only cardiopulmonary resuscitation (CCO-CPR) is recommended for lay bystanders, fatigue is easily produced during CCO-CPR. If CCO-CPR can be performed at a lower intensity of exercise, higher resistance to fatigue is expected. Since chest compression is considered to be a submaximal upper body exercise in a steady rhythm and since the unit of load for chest compression is expressed as work rate, we investigated the possibility that peak work rate of the upper body determines the level of exercise intensity during CCO-CPR.

Methods: Twelve sedentary individuals (group Se), 11 rugby players (group R), and 11 swimmers (group Sw) performed 10-min CCO-CPR, and heart rate (HR) and rating of perceived exertion (RPE) were measured as indices of exercise intensity. Multiple linear regression analysis was carried out to assess potential relationships of upper body weight, peak lumbar extension force, peak work rate, and peak oxygen uptake recorded during arm-crank exercise with $H R$ and RPE during CCO-CPR.

Results: Values of peak work rate during arm-crank exercise (Peak WR-AC) in group Se, group R, and group Sw were $108 \pm 12,139 \pm 27$, and $146 \pm 24$ watts, respectively. Values of the latter two groups were significantly higher than the value of group Se (group $R, P<0.01$; group Sw, $P<0.001$ ). HR during CCO-CPR increased with time, reaching $127.8 \pm$ $17.6,114.8 \pm 16.5$, and $118.1 \pm 14.2 \mathrm{bpm}$ at the 10th minute in group Se, group $R$, and group Sw, respectively. On the other hand, RPE during CCO-CPR increased with time, reaching 16.4 $\pm 1.4,15.4 \pm 1.7$, and 13.9 \pm 2.2 at the 10th minute in group Se, group R, and group SW, respectively. Multiple linear regression analysis showed that only peak WR-AC affects both HR and RPE at the 10th minute of CCO-CPR (HR, $r=-0.458 ; P<0.01 ; \mathrm{RPE}, r=-0.384, P<0.05)$.

Conclusions: The degree of exercise intensity during CCO-CPR is lower in individuals who have a higher peak work rate of the upper body.
\end{abstract}

Keywords: Continuous chest compression, Upper body, Physical training, Fatigue

\section{Background}

Cardiopulmonary resuscitation (CPR) by bystanders provides a favorable outcome after out-of-hospital cardiac arrest [1-6]. In countries such as Japan with an increasing proportion of elderly people in the population, it is expected that the number of elderly people with out-ofhospital cardiac arrest will increase [5]. Thus, the effectiveness of bystander CPR for elderly people $[1,5]$ is particularly important in an aging society. However, the

\footnotetext{
* Correspondence: hisaoga@isc.chubu.ac.jp

Department of Lifelong Sports for Health, College of Life and Health

Sciences, Chubu University, 1200 Matsumoto-cho, Kasugai, Aichi 487-8501,
} Japan
Bystanders would be more willing to perform chestcompression-only CPR (CCO-CPR) than conventional CPR consisting of chest compression (CC) and rescue breathing [8]. Thus, it is expected that the rate of bystander CPR could be improved by encouraging the use of CCO-CPR [9]. Indeed, a recent study has shown that dispatcher instruction of CCO-CPR increases actual provision of bystander CPR compared to dispatcher instruction of conventional CPR [10]. It has also been demonstrated that CCO-CPR was associated with a more favorable outcome than was conventional CPR $[2,6]$. 
On the other hand, one important issue is that more fatigue is produced by CCO-CPR than by conventional CPR [11]. If CCO-CPR can be performed at a lower intensity of exercise, higher resistance to fatigue is expected [12]. It has been shown that heart rate (HR) during $\mathrm{CCO}-\mathrm{CPR}$ is lower in individuals with higher cardiorespiratory fitness who have performed moderate aerobic training such as running, cycling, or swimming [12]. In addition, muscle strength [13, 14] and body weight [15] are possible factors affecting exercise intensity during CCO-CPR. Since physical exertion during CC strains the upper part of the body more than the lower part of the body [16], it is likely that physical fitness of the upper body is an important determinant of exercise intensity during CCO-CPR. To date, however, the kinds of physical fitness of the upper body, e.g., endurance, muscle strength, body weight, or other factors, that affect exercise intensity during $\mathrm{CCO}-\mathrm{CPR}$ have not been fully determined.

Because HR during CCO-CPR has been shown to be a submaximal level [11-15], CC is considered to be a submaximal upper body exercise in a steady rhythm. The unit of load for CC is expressed as work rate [17]. Thus, it is possible that peak work rate of the upper body, which can be increased by upper body training, determines the level of exercise intensity during $\mathrm{CCO}-\mathrm{CPR}$ because relative work rate during CCO-CPR becomes lower with higher peak work rate of the upper body. The purpose of the present study was to examine the relationship between peak work rate of the upper body and exercise intensity during CCO-CPR. In the present study, we used HR and rating of perceived exertion (RPE) of Borg's scale as indices of exercise intensity and compared the levels of exercise intensity during CCO-CPR in upper-body-trained individuals, i.e., rugby players and swimmers, with the levels in sedentary individuals. The reason why two groups of the upper-body-trained individuals were recruited was to determine the effect of possible differences in muscle strength and body weight of the upper body on exercise intensity during CCO-CPR based on the assumption that rugby players have more muscle strength and body weight of the upper body.

\section{Methods}

\section{Subjects}

Healthy male university students $(n=34)$ participated in the present study. The subjects included sedentary individuals (group Se, $n=12$ ), rugby players (group $\mathrm{R}, n=11$ ), and swimmers (group Sw, $n=11$ ) (Table 1). Subjects in group R and group $\mathrm{Sw}$ had more than 4 years of experience in their sports. The subjects in group $\mathrm{R}$ participated in field training for 4-6 days per week and in muscular training for 2-6 days per week. The workout sessions in field training and muscular training per week amounted to 8-14 and 3-10 h, respectively. The subjects in group Sw participated in pool training for 3-6 days per week and in muscular training for $0-5$ days per week. The workout sessions in pool training and muscular training per week amounted to $6-12$ and $0-5$ h, respectively. All of the subjects were nonsmokers and had taken a CPR course less than five times before the experiment. The study was conducted in accordance with the Helsinki Declaration and was approved by the Ethics Committee of Chubu University in Kasugai-shi, Aichi, Japan. Voluntary

Table 1 Physical characteristics of the subjects

\begin{tabular}{|c|c|c|c|c|}
\hline & & Sedentary individuals $(n=12)$ & Rugby players $(n=11)$ & Swimmers $(n=11)$ \\
\hline Age & (years) & $20 \pm 1$ & $20 \pm 1$ & $19 \pm 1$ \\
\hline Height & $(\mathrm{cm})$ & $170.5 \pm 6.2$ & $172.0 \pm 5.5$ & $171.6 \pm 6.0$ \\
\hline Weight & $(\mathrm{kg})$ & $62.29 \pm 8.56^{b b b}$ & $84.06 \pm 13.17^{\text {aaa, } c c c}$ & $66.09 \pm 8.92^{b b b}$ \\
\hline Body mass index & $\left(\mathrm{kg} \cdot \mathrm{m}^{-1} \cdot \mathrm{m}^{-1}\right)$ & $21.3 \pm 2.0^{\mathrm{bbb}}$ & $28.4 \pm 4.0^{\text {aaa, } с c c}$ & $22.5 \pm 2.8^{\mathrm{bbb}}$ \\
\hline Percent body fat & $(\%)$ & $12.9 \pm 4.9^{b}$ & $18.0 \pm 5.0^{c}$ & $13.9 \pm 4.7$ \\
\hline Whole body muscle mass & $(\mathrm{kg})$ & $51.14 \pm 4.36^{\mathrm{bbb}}$ & $64.91 \pm 7.19^{\text {aaa, } c c c}$ & $53.67 \pm 5.12^{\mathrm{bbb}}$ \\
\hline Upper body weight & $(\mathrm{kg})$ & $36.18 \pm 5.20^{\mathrm{bbb}}$ & $49.48 \pm 8.17^{\text {aaa, } c c c}$ & $38.18 \pm 5.68^{b b b}$ \\
\hline Upper body muscle mass & $(\mathrm{kg})$ & $31.30 \pm 2.61^{\mathrm{bbb}}$ & $39.90 \pm 4.80^{\text {aaa, } c c c}$ & $32.63 \pm 3.41^{\mathrm{bbb}}$ \\
\hline Peak WR-AC & (watt) & $108 \pm 12^{\mathrm{bb}, \mathrm{ccc}}$ & $139 \pm 27^{\text {aa }}$ & $146 \pm 24^{\text {aaa }}$ \\
\hline Peak $\dot{V} \mathrm{O}_{2-\mathrm{AC}}$ & $\left(\mathrm{ml} \cdot \mathrm{min}^{-1}\right)$ & $1940 \pm 297^{b, c c c}$ & $2441 \pm 510^{a}$ & $2724 \pm 394^{\text {aaa }}$ \\
\hline Relative peak $\dot{\mathrm{V}} \mathrm{O}_{2-\mathrm{AC}}$ & $\left(\mathrm{ml} \cdot \mathrm{min}^{-1} \cdot \mathrm{kg}^{-1}\right)$ & $38.05 \pm 5.79^{c c c}$ & $37.63 \pm 6.67^{\mathrm{ccc}}$ & $50.82 \pm 6.17^{a a a, b b b}$ \\
\hline Peak ISLE & (kgf) & $121 \pm 14^{b}$ & $152 \pm 29^{a, c}$ & $118 \pm 37^{b}$ \\
\hline
\end{tabular}

Values are means \pm standard deviation

Peak $W R_{-A C}$ peak work rate during arm-crank exercise, Peak $\dot{V} \mathrm{O}_{2-\mathrm{AC}}$ peak oxygen uptake during arm-crank exercise, Peak ISLE peak isometric strength of lumbar extension

${ }^{\text {a }} P<0.05$, aa $P<0.01$, and aaa $P<0.001$, compared to the value in the group of sedentary individuals

${ }^{\mathrm{b}} P<0.05,{ }^{\mathrm{bb}} P<0.01$, and ${ }^{\mathrm{bbb}} P<0.001$, compared to the value in the group of rugby players

${ }^{c} P<0.05,{ }^{c c} P<0.01$, and ${ }^{c c c} P<0.001$, respectively, compared to the value in the group of swimmers 
consent for participation in this study under the ethics approval was obtained from all subjects after they were informed of the purpose of the experiment, the procedure, and possible risks.

\section{Measurements}

Each subject was studied on three different days. On each of the experimental days, the subjects refrained from eating for at least $3 \mathrm{~h}$ before the test, from taking caffeine for at least $5 \mathrm{~h}$ before the test, and from drinking alcohol and doing heavy exercise for $12 \mathrm{~h}$ before the test. All measurements were completed within 24 days.

On the first day, height, weight, and body composition were measured. A multifrequency bioelectrical impedance analyzer (MC-190; TANITA, Tokyo, Japan) was used for measurement of weight and for calculation of body mass index and muscle and fat masses of the four limbs and trunk. Results for body composition obtained by a bioelectrical impedance method using BC-418, also produced by TANITA, have been shown to correlate well with results obtained from dual energy X-ray absorptiometry [18]. According to TANITA, the accuracy of estimates of the composition of each body part produced by MC-190 is equal to that of estimates produced by BC-418 because both use the same system [19]. Thus, estimates from a multifrequency bioelectrical impedance method are considered to be accurate and valid. In the present study, whole body muscle mass, upper body muscle mass, and upper body weight were calculated as the sum of muscle masses of the four limbs and trunk, as the sum of the muscle of the upper limbs and trunk, and as the sum of the muscle and fat masses of the upper limbs and trunk, respectively.

On the second day, peak isometric strength of lumbar extension (Peak ISLE) was determined in a standing posture with lumbar flexion at $30^{\circ}$ using a dynamometer (T.K.K.5710C; Takei, Niigata, Japan) because it is assumed that not only back muscles but also muscles of the upper limbs and chest contribute to peak ISLE [20] and indeed because various upper body muscles are active during CC $[15,21]$. With a sufficient rest period after peak ISLE measurement, the subjects performed ramp exercise in a sitting position using an arm-crank ergometer (Angio V2; Lode, Groningen, the Netherlands) to determine peak work rate and peak oxygen uptake during arm-crank exercise (Peak WR $\mathrm{WC}_{-\mathrm{AC}}$ and Peak $\dot{\mathrm{VO}}_{2-\mathrm{AC}}$, respectively). The center of the ergometer shaft was positioned at the level of the acromion. After 4 min of 10 watt-warm up, the workload was increased by 10 watts every minute, and rpm was set at 60 . The subjects were encouraged to maximize use of their whole upper body muscles during arm-crank exercise according to the method described by Sawka [22]. Arm-crank exercise was terminated when rpm fell below
50 due to exhaustion. Pulmonary oxygen uptake was measured using a respiratory gas analyzer (AE-300S; Minato Medical Science, Osaka, Japan). Peak $\dot{\mathrm{VO}}_{2-\mathrm{AC}}$ was expressed as a relative term by dividing peak $\dot{\mathrm{VO}_{2-\mathrm{AC}}}$ by whole body muscle mass $\left(\mathrm{ml} \cdot \mathrm{min}^{-1} \cdot \mathrm{kg}^{-1}\right)$. All measurements were made in a room with the temperature set at a comfortable temperature for each subject $\left(20 \sim 27.5^{\circ} \mathrm{C}\right)$.

After the end of measurements on the first and second days, short (about $3 \mathrm{~min}$ ) CCO-CPR practice sessions were performed so that the subjects would be able to maintain the prescribed compression rate, compression depth, and recoil and would be able to smoothly answer RPE for the CCO-CPR test to be performed on the third day.

At least 3 days after measurements on the second day, the CCO-CPR test was performed in a room with the temperature set at a comfortable temperature for each subject $\left(21 \sim 26{ }^{\circ} \mathrm{C}\right)$. We used a CPR skill report system consisting of a manikin (CPR501 APPA-Kun Pro; Alexon, Itami, Japan) and a personal computer with dedicated software installed. The same type of manikin has been used previously [23]. The manikin consists of only the thorax portion, and the size is 320 (W) $\mathrm{mm} \times 255$ (D) $\mathrm{mm} \times 230(\mathrm{H}) \mathrm{mm}$. Thorax resistance is provided by the combination of a spring and air. The time course change in $\mathrm{CC}$ depth is displayed in real time on the screen of the personal computer, and the data are stored at $200 \mathrm{~Hz}$ on the personal computer. The depth-force relationship was measured by the manufacturer in the following way. An aluminum plate was set on the standard compression point of the manikin. The size of the plate was $83 \mathrm{~mm} \times 40 \mathrm{~mm}$. This size is assumed to be equal to the contact area of the hand during actual chest compression. The plate was pushed using a cylinder with a load cell attached to the tip of the cylinder. The depthforce relationship was measured every $10 \mathrm{~mm}$ in depth up to $60 \mathrm{~mm}$ in depth.

The compression depth-force relationship measured by the manufacturer is linear and is described by the following equation:

$$
\begin{aligned}
& \text { Compression force required }(\mathrm{kgf}) \\
& \quad=0.6797 \times \text { Compression depth }(\mathrm{mm})-2.3067
\end{aligned}
$$

Equation 1 indicates that the force required to reach a depth of $50 \mathrm{~mm}$ is about $32 \mathrm{kgf}$. This value corresponds to the force required to reach a depth of $50 \mathrm{~mm}$ for human males at $60 \pm 16$ years of age $(n=26,30.5 \pm 8.8 \mathrm{kgf})$ according to the report by Retzer et al. [24].

Each subject rested in a sitting position on the floor for $3 \mathrm{~min}$ and then performed 10-min CCO-CPR while kneeling beside a manikin on the floor. This compression 


\section{Results}

Physical characteristics in the three groups (Table 1)

Group $\mathrm{R}$ showed significantly larger values in weight $(P<0.001)$, body mass index $(P<0.001)$, whole body muscle mass $(P<0.001)$, upper body weight $(P<0.001)$, upper body muscle mass $(P<0.001)$, and peak ISLE $(P<0.05)$ than those in the other two groups. On the other hand, group $\mathrm{Sw}$ showed a significantly larger value in relative peak $\dot{\mathrm{VO}}_{2-\mathrm{AC}}$ than those in the other two groups $(P<0.001)$. Peak $W_{-A C}$ was significantly larger in group $\mathrm{R}$ and group $\mathrm{Sw}$ than in group $\mathrm{Se}$ (group $\mathrm{R}, P<0.01$ and group $\mathrm{Sw}, P<0.001$ ). There was a significant positive relationship between upper body muscle mass and peak ISLE $(r=0.72, P<0.001)$. The relationship between peak ISLE and peak WR-AC was not significant.

\section{CCO-CPR}

Compression rate, $\mathrm{CC}$ quality-depth, and $\mathrm{CC}$ qualityrecoil from the first minute to the last minute of $\mathrm{CCO}$ CPR for all subjects ranged from 108 to 119 compressions/min, from 68 to $100 \%$, and from 93 to $100 \%$, respectively. There was no main effect of group or time, and there was no interaction in the three parameters. Overall averages (34 subjects $\times 10$ time points) of compression rate, $\mathrm{CC}$ quality-depth, and $\mathrm{CC}$ quality-recoil were $110 \pm 1$ compressions/min, $99 \pm 4 \%$, and $99 \pm 1 \%$, respectively, indicating good qualities of compression depth and recoil throughout the 10-min CCO-CPR. Figure 1 shows $\mathrm{WR}_{-\mathrm{CC}}$ during CCO-CPR. There was no main effect of group or time, and there was no interaction. The averages of $\mathrm{WR}_{-\mathrm{CC}}$ during $\mathrm{CCO}-\mathrm{CPR}$ ranged from 123 to 143 watts.

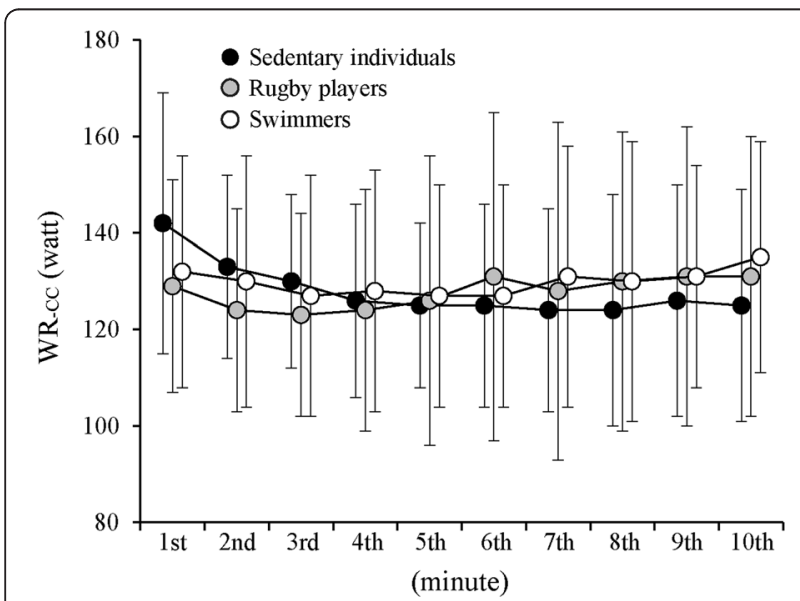

Fig. 1 Comparisons of changes in work rate during 10-min chest compressions between groups. WR-cc work rate of chest compression
Figure 2 shows $\mathrm{HR}$ and RPE responses during CCO-CPR. HR increased with time up to $127.8 \pm 17.6$, $114.8 \pm 6.5$, and $118.1 \pm 14.2 \mathrm{bpm}$ at the 10 th minute in group Se, group $\mathrm{R}$, and group $\mathrm{Sw}$, respectively. Although HR level tended to be higher in group Se than in the other two groups, there was no significant difference between the three groups. Only a significant main effect for time was observed. On the other hand, RPE increased with time up to $16.4 \pm 1.4,15.4 \pm 1.7$, and $13.9 \pm 2.2$ at the 10th minute in group Se, group $\mathrm{R}$, and group $\mathrm{Sw}$, respectively. RPEs from the sixth minute to last minute in group $\mathrm{Sw}$ were significantly lower than those in group $\operatorname{Se}(P<0.05)$. Multiple linear regression analysis showed that $\mathrm{HR}$ at all time points of CCO-CPR can be explained only by peak WR-AC, and the analysis showed that RPE level at the 2nd minute and from the 6th minute to the 10th

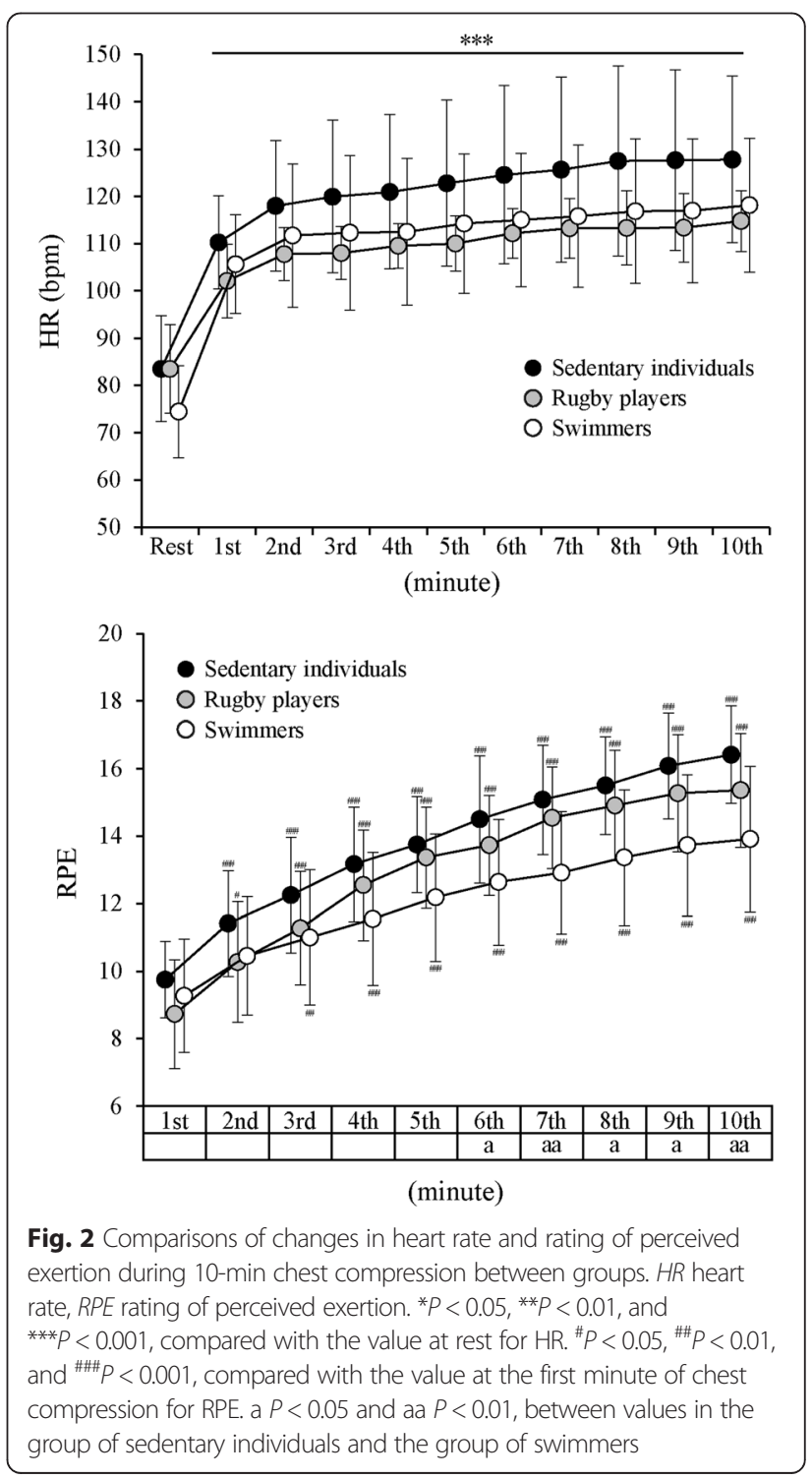


minute of CCO-CPR can also be explained only by peak WR-AC. Standardized partial regression coefficients ranged from -0.421 to -0.482 for $\operatorname{HR}(P<0.01)$ and from -0.340 to -0.463 for RPE $(P<0.05)$. RPE level at the first min was determined by upper body weight, but none of the factors could determine RPE levels from the third to the fifth min.

There was a feeling of breathlessness in 5 of the 12 subjects in group Se (41.7\%), in 5 of the 11 subjects in group R (45.5\%), and in 5 of the 11 subjects in group Sw (45.5\%). On the other hand, there was a feeling of fatigue of the arm in 11 of the 12 subjects in group Se (91.7\%), in 10 of the 11 subjects in group R, (90.9\%), and in 5 of the 11 subjects in group Sw (45.5\%).

In the CCO-CPR test of the additional experiment, values of $\dot{\mathrm{V}}_{2}$ at rest in group Se, group $\mathrm{R}$, and group Sw were $280 \pm 39,345 \pm 62$, and $300 \pm 32 \mathrm{ml} \cdot \mathrm{min}^{-1}$, respectively. $\dot{\mathrm{VO}}_{2}$ increased with time, reaching $1258 \pm$ $162,1461 \pm 260$, and $1231 \pm 109 \mathrm{ml} \cdot \mathrm{min}^{-1}$ at the 10 th minute of CCO-CPR in group Se, group R, and group $\mathrm{Sw}$, respectively (Table 2). Although there was no significant difference in estimated WR $\mathrm{CC}_{\text {-C }}$ among the three groups, estimated relative $\mathrm{WR}_{-\mathrm{CC}}$ was significantly lower in group $\mathrm{R}$ and group $\mathrm{Sw}$ than that in group $\mathrm{Se}$ (group $\mathrm{R}, P<0.05$ and group $\mathrm{Sw}, P<0.001$ ) (Table 2). Estimated relative $\mathrm{WR}_{\text {-CC }}$ ranged from 37 to $96 \%$ across all subjects. Figure 3 shows the relationship between estimated relative $W_{-C C}$ and $H R$ at the 10th minute. There was a strong positive linear relationship between the two variables $(R=0.75, P<0.001)$, although HR at the 10th minute was not significantly related to estimated $W_{-} R_{-C C}$ itself. On the other hand, there was no significant relationship between estimated $W R_{-C C}$ and RPE or between estimated relative $\mathrm{WR}_{-\mathrm{CC}}$ and RPE.

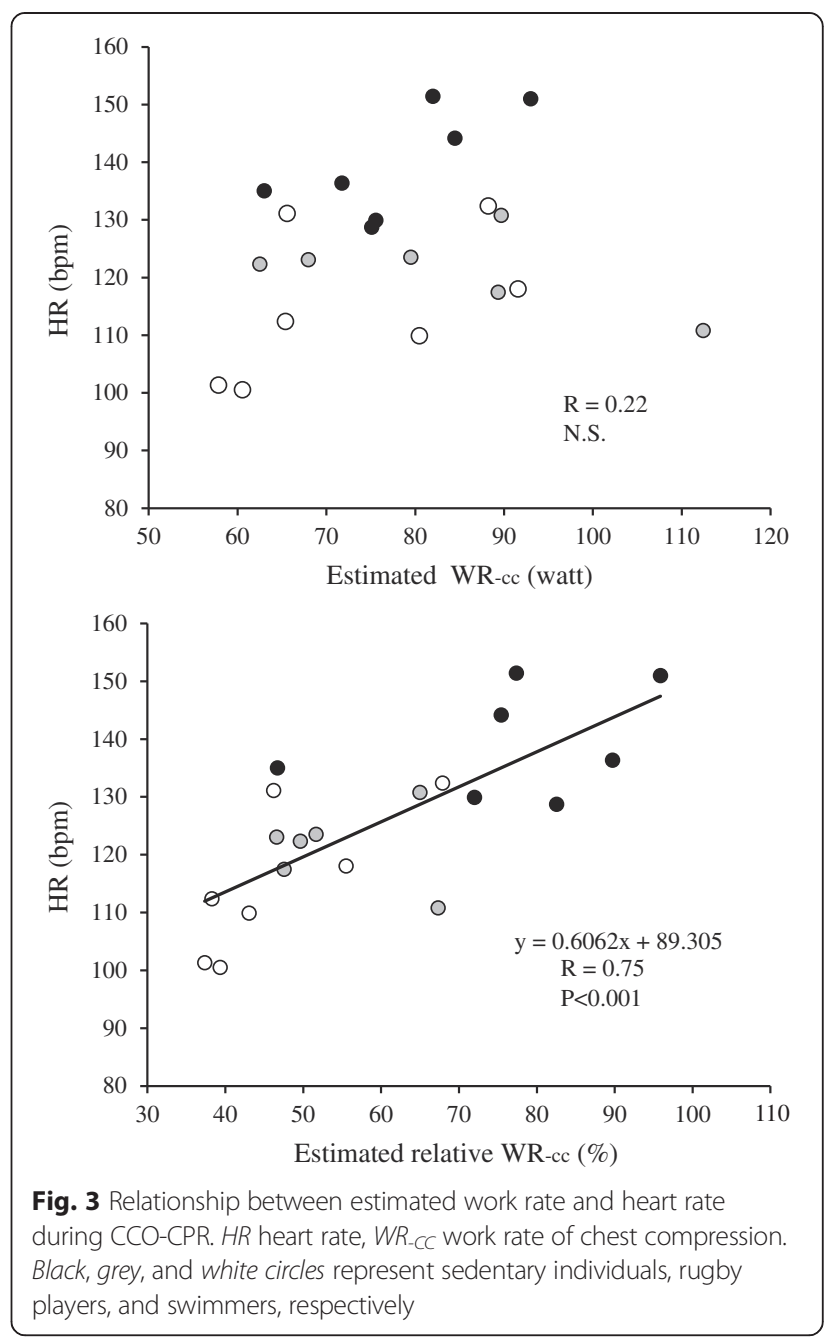

Table 2 Results in the ramp arm-crank exercise and CCO-CPR of the additional experiment

\begin{tabular}{|c|c|c|c|c|c|}
\hline & & & Sedentary individuals $(n=7)$ & Rugby players $(n=6)$ & Swimmers $(n=7)$ \\
\hline \multirow[t]{2}{*}{ Ramp exercise } & Peak WR-AC & (watt) & $104 \pm 17^{\mathrm{bbb}, c c c}$ & $153 \pm 22^{\text {aaa }}$ & $158 \pm 19^{\text {aaa }}$ \\
\hline & Peak $\dot{V} \mathrm{O}_{2-\mathrm{AC}}$ & $\left(\mathrm{ml} \cdot \mathrm{min}^{-1}\right)$ & $1753 \pm 234^{\mathrm{bbb}, ~ c c c ~}$ & $2615 \pm 254^{\text {aaa }}$ & $2518 \pm 298^{\text {aaa }}$ \\
\hline \multirow[t]{6}{*}{ CCO-CPR } & $\dot{V} \mathrm{O}_{2}$ at the 10 th $\min$ & $\left(\mathrm{ml} \cdot \mathrm{min}^{-1}\right)$ & $1258 \pm 162$ & $1461 \pm 260$ & $1231 \pm 109$ \\
\hline & Ratio of $\dot{V} \mathrm{O}_{2}$ at the 10 th min to Peak $\dot{V} \mathrm{O}_{2-\mathrm{AC}}$ & (\%) & $73 \pm 13^{\mathrm{b}, ~ c c c ~}$ & $56 \pm 7^{a}$ & $49 \pm 7^{\text {aаa }}$ \\
\hline & HR at the 10th min & (bpm) & $140 \pm 9^{b, c c c}$ & $121 \pm 7^{\mathrm{a}}$ & $115 \pm 13^{\text {aaa }}$ \\
\hline & RPE at the 10th min & & $15.3 \pm 1.6$ & $14.2 \pm 1.7$ & $13.9 \pm 1.2$ \\
\hline & Estimated WR-cc & (watt) & $78 \pm 10$ & $84 \pm 18$ & $73 \pm 14$ \\
\hline & Estimated Relative WR-cc & $(\%)$ & $77 \pm 16^{\mathrm{b}, c c c}$ & $55 \pm 9^{a}$ & $47 \pm 11^{\text {aaa }}$ \\
\hline
\end{tabular}

Values are means \pm standard deviation

Peak $W R_{-A C}$ peak work rate during arm-crank exercise, Peak $\dot{V} \mathrm{O}_{2-A C}$ peak oxygen uptake during arm-crank exercise, $C C O-C P R$ chest-compression-only cardiopulmonary resuscitation, $W R_{\text {-cc }}$ work rate of chest compression

${ }^{\text {a }} P<0.05$, aa $P<0.01$, and aaa $P<0.001$, compared to the value in the group of sedentary individuals

${ }^{\mathrm{b}} P<0.05$, ${ }^{\mathrm{bb}} P<0.01$, and ${ }^{\mathrm{bbb}} P<0.001$, compared to the value in the group of rugby players

${ }^{c} P<0.05,{ }^{c c} P<0.01$, and ${ }^{c c c} P<0.001$, compared to the value in the group of swimmers 


\section{Discussion}

\section{Comparison of levels of physical fitness in the three groups}

Upper body muscle mass was closely related to peak ISLE, suggesting that peak ISLE reflects muscle strength of the upper body and that subjects in group $\mathrm{R}$ could exert higher peak ISLE due to greater mass of upper body muscles. However, partial correlation analysis showed that peak WR-AC was not related to peak ISLE in part because peak ISLE was significantly lower in group $\mathrm{Sw}$ than that in group $\mathrm{R}$ regardless of the fact that peak $W_{-A C}$ in group $S w$ and that in group $R$ were almost the same. It is possible that subjects in group $\mathrm{Sw}$ could have exerted force during arm-crank exercise that was not properly reflected by peak ISLE because the subjects were encouraged to maximize use of their whole upper body muscles and because more muscle mass might have been recruited in subjects in group Sw possibly due to the similarity of movement patterns for swimming stroke (especially crawl stroke) and armcrank exercise.

\section{Determinants of degree of exercise intensity during chest compression}

The unit of load is expressed as work rate in CCO-CPR [17]. Badaki-Makun et al. reported that peak work rates during 10-min CCO-CPR were 144.1 watts in a child manikin and 166.5 watts in an adult manikin [17]. In the present study, on the other hand, the peak value of average WR $\mathrm{WCC}_{-\mathrm{C}}$ was 143 watts, corresponding to the value during CCO-CPR using a child manikin [17].

The unit of load of arm-crank exercise is also expressed as work rate. In the present study, only peak WR-AC was a determinant of $\mathrm{HR}$ at all time points of CCO-CPR. Although arm-crank exercise and $\mathrm{CC}$ are different types of exercise, both are upper body exercises in a steady rhythm. Thus, it is possible that HR becomes lower with higher peak $W R_{-A C}$ due to a reduction of relative work rate during CCO-CPR. In fact, subjects with lower estimated relative $W_{-C C}$ showed lower $H R$. In the present study, RPE level in the latter 5 min of CCO-CPR was also determined only by peak WR-AC. However, RPE in the former $5 \mathrm{~min}$ of $\mathrm{CCO}-\mathrm{CPR}$ except $\mathrm{RPE}$ at the second minute of CCO-CPR could not be determined by peak $W_{-A C}$. In addition, there was no significant relationship between estimated relative $\mathrm{WR}_{-\mathrm{CC}}$ and RPE level. Thus, the results suggested that RPE level is not directly related to peak WR-AC. Pierce et al. [27] examined local muscular and cardiopulmonary strains separately by using Borg's RPE scale during 10-min conventional CPR. They found that the RPE for local muscular strains was higher than the RPE for cardiopulmonary strain. Thus, RPE during $\mathrm{CCO}-\mathrm{CPR}$ might have been greatly influenced by local muscle strain in the present study, although we instructed the subjects to give overall RPE including strains of local muscle and cardiopulmonary systems. In support of this possibility, RPE levels from the sixth minute to the last minute were lower in group $\mathrm{Sw}$, in which fewer subjects reported feeling arm fatigue immediately after the end of CCO-CPR. If RPE during CCO-CPR is determined mainly by local muscle fatigue, no significant difference in RPE between the three groups in the former $5 \mathrm{~min}$ of $\mathrm{CCO}-$ CPR might have been due to little difference in local muscle fatigue.

Muscle strength $[13,14]$ and weight [15] are possible factors affecting exercise intensity during CCO-CPR. In the present study, although upper body weight or muscle strength as evaluated from peak ISLE was not an explanatory variable for $\mathrm{HR}$ and RPE during CCO-CPR, higher muscle strength will serve to increase peak WR-AC. In addition, large upper body weight will enable performance of CC with less muscle strength due to the action of gravity. Thus, it is likely that muscle strength and upper body weight are remote causes of a decrease in exercise intensity during $\mathrm{CCO}-\mathrm{CPR}$.

\section{Implications and limitations}

Previous reports have pointed out the need for a minimum level of physical conditioning in CPR providers because a higher level of physical fitness has a positive impact on the quality of CCO-CPR [12-14]. In the present study, peak $\mathrm{WR}_{-\mathrm{AC}}$, which determines HR during CCO-CPR, was larger in group $\mathrm{R}$ and group $\mathrm{Sw}$ than that in group $\mathrm{Se}$. In addition, group Sw showed a low RPE level during CCOCPR compared to that in group Se. These findings show the importance of physical conditioning of the upper body for the quality of CCO-CPR. However, although upper body weight and peak ISLE were lower in group Sw than those in group $\mathrm{R}$, the subjects in group $\mathrm{Sw}$ could perform CCO-CPR with levels of HR and RPE similar to those in subjects in group $R$, indicating that training that enhances muscle strength and increases body weight of the upper body is not necessarily required for performance of CCOCPR with a low level of exercise intensity. Our findings will eventually contribute to education and training of singlerescuer bystander CPR for potential CPR providers such as citizens and all health professionals involved in pre- and inhospital emergency medicine and critical care. Furthermore, we believe that our findings are important in terms of life-saving for elderly people in an aging society considering that an issue in an aging society is an increase in the number of elderly patients with out-of-hospital cardiac arrest [5] and that CCO-CPR is a useful tool for elderly patients $[1,5]$. In the present study, we focused on singlerescuer bystander CPR. However, it should be noted that participation of more than one bystander and changes of their roles would lead to an increase in the rate of success 
of CPR through maintenance of the quality of chest compressions during CCO-CPR [28].

A major limitation of this study is that the results cannot be extended to CCO-CPR by humans with higher chest resistance. In the present study, a force of about $32 \mathrm{kgf}$ was required for $50 \mathrm{~mm}$ depth compression. In this situation, estimated WR-CC was a submaximal level ran-

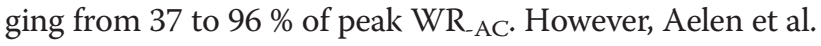
[29] demonstrated that compression force required for a depth of $50 \mathrm{~mm}$ ranges from 14.0 to $96.4 \mathrm{kgf}$ in humans. In the case of compressions of a stiffer chest, exercise intensity will increase in the maximal or supramaximal level, causing difficulty in continuation of CCO-CPR. Therefore, endurance capacity for sustaining a higher peak work rate of the upper body may be needed during CCO-CPR for a stiffer chest. Further study is needed to clarify what kind of this possibility.

\section{Conclusions}

$\mathrm{HR}$ during CCO-CPR is lower in individuals who have a higher peak work rate of the upper body due to reduction of relative work rate during CCO-CPR. Since upper-bodytrained individuals have the potential not only to exert higher peak $\mathrm{WR}_{\mathrm{AC}}$ but also to execute CCO-CPR with a low level of RPE, upper body training is useful for reduction of exercise intensity during CCO-CPR. However, training that enhances muscle strength and increases body weight of the upper body is not necessarily required for performance of CCO-CPR with a low level of exercise intensity.

\begin{abstract}
Abbreviations
CC: chest compression; CCO-CPR: chest-compression-only cardiopulmonary resuscitation; CPR: cardiopulmonary resuscitation; Group Se: group of sedentary individuals; Group R: group of rugby players; Group Sw: group of swimmers; HR: heart rate; Peak ISLE: peak isometric strength of lumbar extension; Peak $\dot{V}_{O_{2-A c}}$ : peak oxygen uptake during arm-crank exercise; Peak WR-Ac: peak work rate during arm-crank exercise; RPE: rating of perceived exertion; WR-cc: work rate of chest compression.
\end{abstract}

\section{Competing interests}

The authors declare that they have no competing interests.

\section{Authors' contributions}

$\mathrm{HO}$ contributed to all of the works, including conception, design, acquisition of data, execution of the experiment, analysis and interpretation of data, and writing the paper. IF contributed to management of possible risks. TK contributed to management of possible risks and helped to draft the manuscript. All of the authors have read and approved the final manuscript.

\section{Acknowledgement}

This study was supported by Chubu University Grant (A).

Received: 26 March 2015 Accepted: 16 November 2015 Published online: 19 December 2015

\section{References}

1. Akahane M, Tanabe S, Koike S, Ogawa T, Horiguchi H, Yasunaga H, et al. Elderly out-of-hospital cardiac arrest has worse outcomes with a family bystander than a non-family bystander. Int J Emerg Med. 2012;5:41.

2. Bobrow BJ, Spaite DW, Berg RA, Stolz U, Sanders AB, Kern KB, et al. Chest compression-only CPR by lay rescuers and survival from out-of-hospital cardiac arrest. JAMA. 2010;304:1447-54.
3. Iwami T, Kawamura T, Hiraide A, Berg RA, Hayashi Y, Nishiuchi T, et al. Effectiveness of bystander-initiated cardiac-only resuscitation for patients with out-of-hospital cardiac arrest. Circulation. 2007;116:2900-7.

4. Kitamura T, Iwami T, Kawamura T, Nagao K, Tanaka H, Berg RA, et al. Time-dependent effectiveness of chest compression-only and conventional cardiopulmonary resuscitation for out-of-hospital cardiac arrest of cardiac origin. Resuscitation. 2011;82:3-9.

5. Kitamura T, Morita S, Kiyohara K, Nishiyama C, Kajino K, Sakai T, et al. Trends in survival among elderly patients with out-of-hospital cardiac arrest: a prospective, population-based observation from 1999 to 2011 in Osaka. Resuscitation. 2014;85:1432-8

6. SOS-KANTO Study Group. Cardiopulmonary resuscitation by bystanders with chest compression only (SOS-KANTO): an observational study. Lancet. 2007;369:920-6.

7. Abella BS, Aufderheide TP, Eigel B, Hickey RW, Longstreth Jr WT, Nadkarni V, et al. Reducing barriers for implementation of bystander-initiated cardiopulmonary resuscitation: a scientific statement from the American Heart Association for healthcare providers, policymakers, and community leaders regarding the effectiveness of cardiopulmonary resuscitation. Circulation. 2008;117:704-9.

8. Cho GC, Sohn YD, Kang KH, Lee WW, Lim KS, Kim W, et al. The effect of basic life support education on laypersons' willingness in performing bystander hands only cardiopulmonary resuscitation. Resuscitation. 2010;81:691-4.

9. Drager KK. Improving patient outcomes with compression-only CPR: will bystander CPR rates improve? J Emerg Nurs. 2012;38:234-8.

10. Shimamoto T, Iwami T, Kitamura T, Nishiyama C, Sakai T, Nishiuchi T, et al. Dispatcher instruction of chest compression-only CPR increases actual provision of bystander CPR. Resuscitation. 2015;96:9-15.

11. Shin J, Hwang S, Lee H, Park C, Kim Y, Son Y, et al. Comparison of CPR quality and rescuer fatigue between standard 30:2 CPR and chest compression-only CPR: a randomized crossover manikin trial. Scand J Trauma Resusc Emerg Med. 2014;22:59.

12. Lucía A, de las Heras JF, Pérez M, Elvira JC, Carvajal A, Alvarez AJ, et al. The importance of physical fitness in the performance of adequate cardiopulmonary resuscitation. Chest. 1999:115:158-64.

13. Hansen D, Vranckx P, Broekmans T, Eijnde BO, Beckers W, Vandekerckhove P, et al. Physical fitness affects the quality of single operator cardiocerebral resuscitation in healthcare professionals. Eur J Emerg Med. 2012;19:28-34.

14. Ock SM, Kim YM, Chung J, Kim SH. Influence of physical fitness on the performance of 5-min continuous chest compression. Eur J Emerg Med. 2011:18:251-6.

15. Hasegawa T, Daikoku R, Saito S, Saito Y. Relationship between weight of rescuer and quality of chest compression during cardiopulmonary resuscitation. J Physiol Anthropol. 2014;33:16.

16. Russo SG, Neumann P, Reinhardt S, Timmermann A, Niklas A, Quintel M, et al. Impact of physical fitness and biometric data on the quality of external chest compression: a randomised, crossover trial. BMC Emerg Med. 2011;11:20.

17. Badaki-Makun O, Nadel F, Donoghue A, McBride M, Niles D, Seacrist T, et al. Chest compression quality over time in pediatric resuscitations. Pediatrics. 2013;131:e797-804.

18. Pietrobelli A, Rubiano F, St-Onge MP, Heymsfield SB. New bioimpedance analysis system: improved phenotyping with whole-body analysis. Eur J Clin Nutr. 2004:58:1479-84.

19. Kubo T, Suzuki K, Mimura Y, Furujo M, Shiraga $H$, Kanadani T, et al. Evaluation of partial body composition using bioelectrical impedance in Japanese children. Asia Pac J Clin Nutr. 2010;19:594-601.

20. Laboratory of Physical Fitness Standards Tokyo Metropolitan University. New physical fitness standards of Japanese people Ver. 2. Tokyo: Fumaido Publishing Co., Ltd; 2007. in Japanese.

21. Trowbridge C, Parekh JN, Ricard MD, Potts J, Patrickson WC, Cason CL. A randomized cross-over study of the quality of cardiopulmonary resuscitation among females performing 30:2 and hands-only cardiopulmonary resuscitation. BMC Nurs. 2009;8:6.

22. Sawka MN. Physiology of upper body exercise. Exerc Sport Sci Rev. 1986;14:175-211.

23. Hirose $T$, Iwami $T$, Ogura $H$, Matsumoto $H$, Sakai T, Yamamoto $K$, et al. Effectiveness of a simplified cardiopulmonary resuscitation training program for the non-medical staff of a university hospital. Scand J Trauma Resusc Emerg Med. 2014;22:31. 
24. Retzer E, Yuen TC, Cua JL, Edelson DP. Abstract 290: sex disparities in chest compression quality. Circulation. 2011;124:A290.

25. Travers AH, Rea TD, Bobrow BJ, Edelson DP, Berg RA, Sayre MR, et al. Part 4: CPR overview: 2010 American Heart Association Guidelines for Cardiopulmonary Resuscitation and Emergency Cardiovascular Care. Circulation. 2010;122:S676-84.

26. Borg G. Borg's perceived exertion and pain scales. Human Kinetics: Champaign; 1998

27. Pierce EF, Eastman NW, McGowan RW, Legnola ML. Metabolic demands and perceived exertion during cardiopulmonary resuscitation. Percept Mot Skills. 1992;74:323-8.

28. Nishiyama C, Iwami T, Kawamura T, Ando M, Yonemoto N, Hiraide A, et al. Quality of chest compressions during continuous CPR; comparison between chest compression-only CPR and conventional CPR. Resuscitation. 2010;81:1152-5.

29. Aelen P, Paulussen I, Noordergraaf GJ, Woerlee P. Abstract 123: chest stiffness: getting to a $6 \mathrm{~cm}$ compression depth expectation. Circulation. 2013;128:A123.

Submit your next manuscript to BioMed Central and we will help you at every step:

- We accept pre-submission inquiries

- Our selector tool helps you to find the most relevant journal

- We provide round the clock customer support

- Convenient online submission

- Thorough peer review

- Inclusion in PubMed and all major indexing services

- Maximum visibility for your research 